\title{
Association of PDCD6 polymorphisms with the risk of cancer: Evidence from a meta-analysis
}

This article has been corrected. Correction in Oncotarget. 2020; 11:893-893.

Mohammad Hashemi1,2, Gholamreza Bahari², Jarosław Markowski ${ }^{3}$, Andrzej Małecki ${ }^{4}$, Marek J. .os $^{5,8}$ and Saeid Ghavami,7

\footnotetext{
${ }^{1}$ Cellular and Molecular Research Center, Zahedan University of Medical Sciences, Zahedan, Iran

${ }^{2}$ Department of Clinical Biochemistry, School of Medicine, Zahedan University of Medical Sciences, Zahedan, Iran

${ }^{3}$ ENT Department, School of Medicine, Medical University of Silesia in Katowice, Katowice, Poland

${ }^{4}$ Faculty of Physiotherapy, The Jerzy Kukuczka Academy of Physical Education in Katowice, Katowice, Poland

${ }^{5}$ Department of Molecular Biology, School of Pharmacy with the Division of Laboratory Medicine in Sosnowiec, Medical University of Silesia in Katowice, Katowice, Poland

${ }^{6}$ Department of Human Anatomy and Cell Science, Max Rady College of Medicine, Rady Faculty of Health Sciences, University of Manitoba, Winnipeg, MB, Canada

${ }^{7}$ Health Policy Research Center, Institute of Health, Shiraz University of Medical Sciences, Shiraz, Iran

${ }^{8}$ Centre de Biophysique Moléculaire, CNRS, Rue Charles Sadron, Orleans, France

Correspondence to: Mohammad Hashemi, email: mhd.hashemi@gmail.com; hashemim@zaums.ac.ir Marek J. Łos, email: bioappl@gmail.com

Keywords: PDCD6; meta-analysis; cancer; risk; endometrial cancer
}

Received: January 08, $2018 \quad$ Accepted: April 12, $2018 \quad$ Published: May 15, 2018

Copyright: Hashemi et al. This is an open-access article distributed under the terms of the Creative Commons Attribution License 3.0 (CC BY 3.0), which permits unrestricted use, distribution, and reproduction in any medium, provided the original author and source are credited.

\section{ABSTRACT}

This study was designed to evaluate the relationship between Programmed cell death protein 6 (PDCD6) polymorphisms and cancer susceptibility. The online databases were searched for relevant case-control studies published up to November 2017. Review Manage (RevMan) 5.3 was used to conduct the statistical analysis. The pooled odds ratio (OR) with its $95 \%$ confidence interval (CI) was employed to calculate the strength of association. Overall, our results indicate that PDCD6 rs3756712 T>G polymorphism was significantly associated with decreased risk of cancer under codominant $(\mathrm{OR}=0.82,95 \% \mathrm{CI}=0.70-0.96, p=0.01$, TG vs TT; OR $=0.53,95 \% \mathrm{CI}=0.39-0.72, p<0.0001$, GG vs TT $)$, dominant $(\mathrm{OR}=0.76,95 \% \mathrm{CI}=$ $0.66-0.89, p=0.0004$, TG+GG vs TT), recessive $(\mathrm{OR}=0.57,95 \% \mathrm{CI}=0.43-0.78, p$ $=0.0003$, GG vs TT+TG), and allele (OR $=0.76,95 \% \mathrm{CI}=0.67-0.86, p<0.00001$, G vs $T$ ) genetic model. The finding did not support an association between rs4957014 T>G polymorphism of PDCD6, and different cancers risk.

\section{INTRODUCTION}

Cancer is a major public health burden, with an estimate of 14.1 million new cancer cases and 8.2 million cancer-related deaths occurred globally in 2012 [3]. In $2018,1,735,350$ new cancer cases and 609,640 cancer deaths are projected to occur in the United States. It has been reported that over the past decade, the rate of incidence (2005-2014) was nearly linear and without any changes in women, and declined by approximately $2 \%$ annually in men, while the rate of cancer death (20062015 ) was declined by about $1.5 \%$ annually in both men and women [32]. It is estimated that in 2017, 1,688,780 new cancer cases was diagnosed and 600,920 cancer deaths are estimated to occurred in the United States [31]. Although significant progress has been reached in understanding the mechanism and pathogenesis of different types of cancers, the exact etiology is still not completely 
understood. Growing evidences indicate that cancer is a multifactorial disease caused by genetic background and environmental interactions $[4,8]$.

Apoptosis, also known as programmed cell death, is involved in physiological cell death [11]. Many factors contribute in the apoptotic pathway, including caspases, pro- and anti-apoptotic Bcl2 family members, and mitochondrial pro-apoptotic proteins $[5,6,22]$. Defects in the apoptosis machinery may lead to serious disease including cancer, autoimmune disease and drug resistance in tumors $[5,7,26]$.

Programmed cell death protein 6 (PDCD6), located on chromosome 5p15.33 contains 43351 $\mathrm{bp}$, is also known as apoptosis-linked gene-2 ( $A L G$ 2). PDCD6 gene encodes a $22 \mathrm{kDa}$ calcium-binding protein comprising five serially repetitive EF-hand structures. This protein is one of the prototypic members of the penta-EF-hand protein family. Initially, PDCD6 was considered as a pro-apoptotic protein contributing to T-cell receptor-, Fas-, and glucocorticoid- induced programmed cell death $[30,12]$, as well as endoplasmic reticulum stress induced apoptosis during organ formation [25, 18]. In recent years, some PDCD6-interacting proteins have been identified, including Peflin [14], Alix [21], Fas [12] and Annexin XI [28]. However none of them regulates PDCD6 activity, and such factor yet avaits to be identified. Alix and PDCD6 interaction with procaspase- 8 potentiated cell death induction via tumor necrosis factor receptor 1 (TNFR1) [19]. Several studies have examined the expression of PDCD6 in clinical tumor tissues or cell lines, and found that PDCD6 has opposing effects in different tumors. PDCD6 expression was upregulated in tumor tissue samples from lung, breast, colon cancer, and ovarian cancer, which suggested that PDCD6 might be involved in maintenance of cellular viability $[15,10,17,33,24]$. In contrast, decreased PDCD6 expression was detected in non-small cell lung cancer (NSCLC), gastric cancer and HeLa cells [38, 40].

Recently, it has been shown that that miR-124$3 p$ attenuated tumor metastasis by inhibiting PDCD6 expression, and that the miR-124-3p/PDCD6 signaling axis could potentially be a therapeutic target for patients with advanced breast cancer [43]. Another study showed that the over-expression of miR-124 suppressed PDCD6 expression, inhibited cell proliferation, migration and invasion, and induced apoptosis in SKOV3 and OCVAR3 cells in vitro [41]. Furthermorem it has been proposed that miR-183 may function as an oncogene that may increase childhood acute myeloid leukemia (AML) cell proliferation by targeting PDCD6 [37].

Previous studies inspecting the association between PDCD6 gene polymorphisms and cancer indicated inconclusive and contradictory results [9, 45, 44, 42]. Hence, we have performed a meta-analysis on all the published case-control studies to evaluate the association of PDCD6 rs3756712 $\mathrm{T}>\mathrm{G}$ and rs4957014 $\mathrm{T}>\mathrm{G}$ gene polymorphisms with the risk of cancer. Maps of the human PDCD6 gene with polymorphisms positions is illustrated in Figure 1.

\section{METHODOLOGY}

A comprehensive search in PubMed, Web of Science, Scopus, and Google Scholar databases was performed for all articles describing an association between PDCD6 polymorphism and cancer risk published up to November 2017 without language restriction. The search strategy was "cancer, carcinoma, tumor, neoplasm", "PDCD6, programmed cell death 6 ", and "polymorphism, mutation, variant". Figure 2 summarized the process of identifying eligible studies. Relevant studies, eligible for the meta-analysis must meet the following criteria: 1) Original case-control studies of the correlation between the PDCD6 polymorphism and cancer; 2) studies provided sufficient information of the genotype frequencies of PDCD6 polymorphism in both cases and controls; 3) the studies have not repeated reports in the same population. The criteria for exclusion were: 1 ) the articles that describe case reports, reviews, overlapped data, animal or mechanism studies for PDCD6 polymorphism and cancer; 2) no genotype frequency or genotype information were provided for PDCD6 polymorphism and cancer; 3) insufficient information for data extraction.

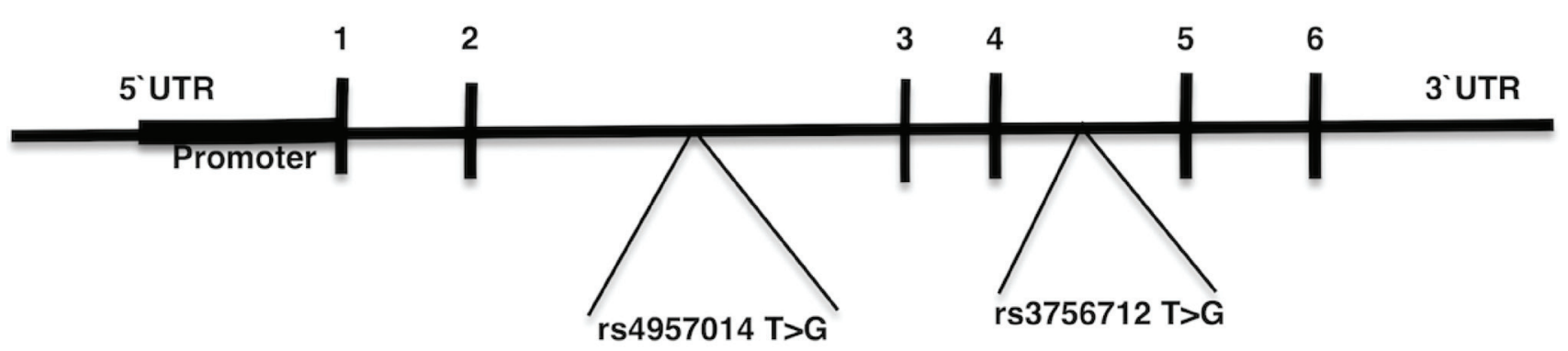

Figure 1: Map of the human PDCD6 gene with polymorphisms positions indicated. Exons $1-6$ are numbered and represented by black boxes. Both of the rs $3756712 \mathrm{~T}>\mathrm{G}$ and $\mathrm{rs} 4957014 \mathrm{~T}>\mathrm{G}$ variants positioned in intron region. 


\section{Data extraction}

Extraction of the data has been conducted by two independent scientists. The data were collected from each study including the first author's name, publication year, ethnicity of participants, the sample size, and the genotype and allele frequencies of cases and controls.

\section{Statistical analysis}

Meta-analysis was carried out using Revman 5.3 software, which was provided by the Cochrane Collaboration (Version 5.3. Copenhagen: The Nordic Cochrane Centre, the Cochrane Collaboration, 2014) and STATA 14.1 software (Stata Corporation, College Station, TX, USA). All of the data in the studies are dichotomous data, which has been expressed as odds ratios (ORs) with 95\% confidence intervals (CIs) to assess the association between the polymorphisms and cancer. Hardy-Weinberg equilibrium (HWE) for each study was determined by the chi-square tests of control group data. Odds ratios (ORs) and 95\% confidence intervals (CIs) were pooled to evaluate the association between the polymorphisms and risk of cancer. For each polymorphism the ORs were calculated for dominant, codominant, recessive, over-dominant, and allele genetic models. Heterogeneity also assessed using the $\mathrm{I}^{2}$ statistic, interpreted as the proportion of the total variation contributed by interstudy variation, and the Cochran chi-square $Q$-test, with a significance level of $P<0.10$ and $I^{2}>50 \%$. When significant heterogeneity values were returned, the random-effects model (the DerSimonian and Laird method) was used to estimate pooled ORs. Otherwise, the fixed-effects model (the Mantel-Haenszel method) was employed. The significance of the pooled OR was assessed by the $Z$-test, and $P<0.05$ was considered to be statistically significant.

Publication bias was evaluated by funnel plot. The degree of asymmetry was measured using Egger's linear regression test; $p<0.05$ was considered significant publication bias [2]. The characteristics and relevant data of the included studies are shown in Table 1. The genotypes of $P D C D 6$ polymorphisms in controls were all in accordance with HWE $(P>0.05)$ except for Zhou et al. [45] (Table 1).

\section{RESULTS}

\section{Association of PDCD6 rs3756712 T $>G$ and rs4957014 $\mathrm{T}>\mathrm{G}$ polymorphisms and cancer risk}

Four studies [42, 45, 44, 9] reported the association between rs3756712 and rs4957014 polymorphisms and

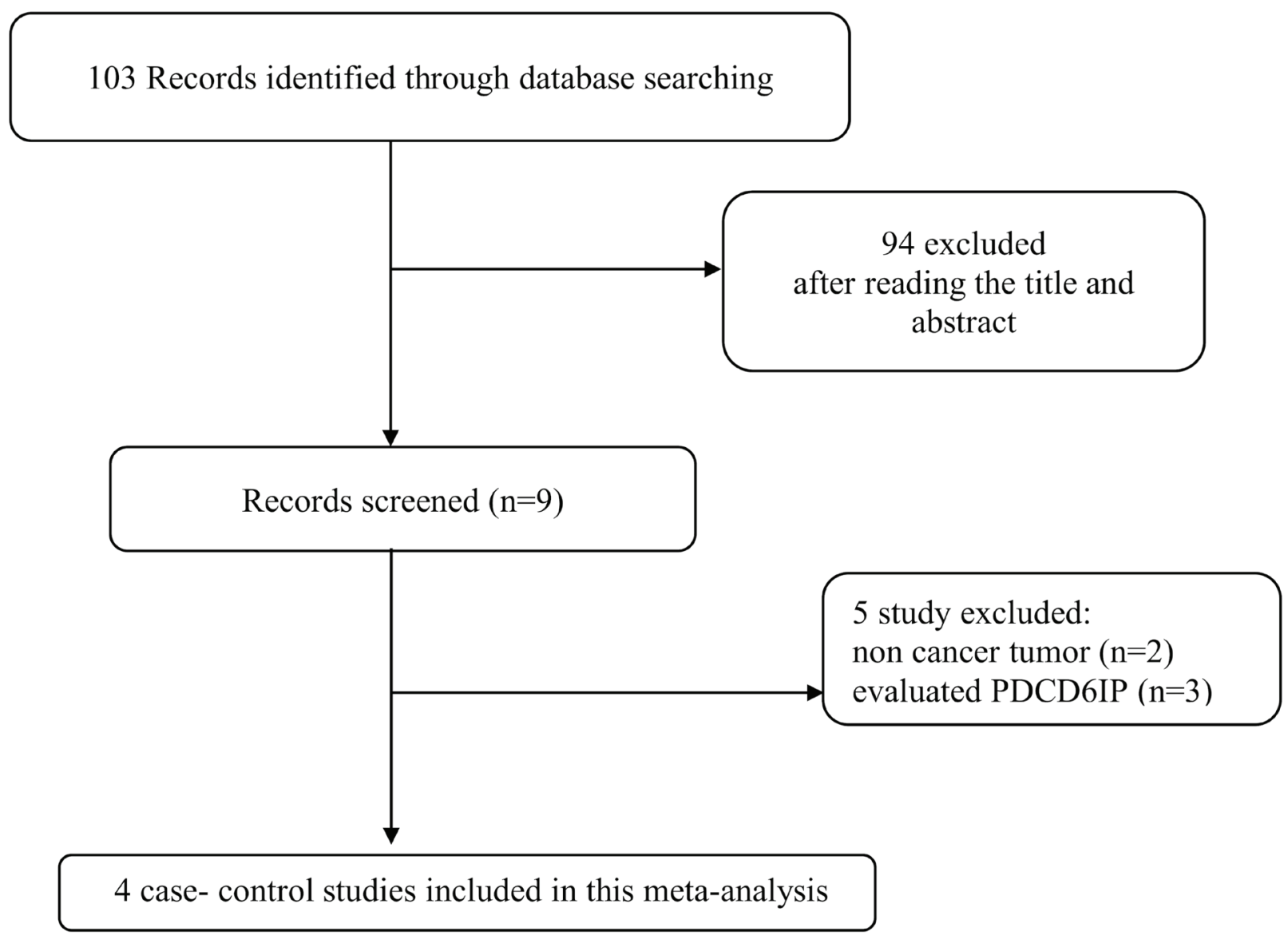

Figure 2: Flow chart of literature screening and selection in the meta-analysis. 
Table 1: Distribution information of genotypes and alleles of all studies included in the meta-analysis for rs3756712 $T>G$ and rs4957014 $T>G$ polymorphisms of programmed cell death 6 (PDCD6)

\begin{tabular}{|c|c|c|c|c|c|c|c|c|c|c|c|c|c|c|c|c|c|c|}
\hline Author & Year & Country & Ethnicity & Cancer type & Source of & Genotyping & Case/control & & & cases & & & & & Contro & & & HWE \\
\hline rs 3756712 & & & & & & & & TT & GT & GG & $\mathrm{T}$ & G & TT & GT & GG & $\mathrm{T}$ & G & \\
\hline Yuan & 2017 & China & Asian & $\begin{array}{l}\text { Endometrial } \\
\text { Cancer }\end{array}$ & HB & PCR-RFLP & $238 / 518$ & 153 & 70 & 15 & 376 & 100 & 290 & 184 & 44 & 764 & 272 & 0.060 \\
\hline Zhou & 2015 & China & Asian & $\begin{array}{l}\text { Cervical squamous } \\
\text { cell carcinoma }\end{array}$ & HB & PCR-RFLP & $328 / 541$ & 202 & 109 & 17 & 513 & 143 & 298 & 195 & 48 & 791 & 291 & 0.053 \\
\hline Zhou & 2014 & China & Asian & Bladder cancer & HB & PCR-RFLP & $332 / 509$ & 214 & 101 & 17 & 529 & 135 & 279 & 183 & 47 & 741 & 277 & 0.037 \\
\hline $\mathrm{He}$ & 2012 & China & Asian & Lung cancer & HB & PCR-RFLP & $302 / 306$ & 168 & 120 & 14 & 456 & 148 & 168 & 111 & 27 & 447 & 165 & 0.167 \\
\hline rs 4957014 & & & & & & & & TT & GT & GG & $\mathrm{T}$ & G & TT & GT & GG & $\mathrm{T}$ & G & \\
\hline Yuan & 2017 & China & Asian & $\begin{array}{l}\text { Endometrial } \\
\text { Cancer }\end{array}$ & HB & PCR-RFLP & $238 / 518$ & 83 & 131 & 24 & 297 & 179 & 234 & 231 & 53 & 699 & 337 & 0.720 \\
\hline Zhou & 2015 & China & Asian & $\begin{array}{l}\text { Cervical squamous } \\
\text { cell carcinoma }\end{array}$ & $\mathrm{HB}$ & PCR-RFLP & $328 / 541$ & 130 & 142 & 56 & 402 & 254 & 243 & 246 & 52 & 732 & 350 & 0.365 \\
\hline Zhou & 2014 & China & Asian & Bladder cancer & $\mathrm{HB}$ & PCR-RFLP & $332 / 509$ & 170 & 125 & 37 & 465 & 199 & 229 & 232 & 48 & 690 & 328 & 0.325 \\
\hline $\mathrm{He}$ & 2012 & China & Asian & Lung cancer & HB & PCR-RFLP & $302 / 306$ & 155 & 124 & 23 & 434 & 170 & 134 & 136 & 36 & 404 & 208 & 0.868 \\
\hline
\end{tabular}

HB, hospital based.

Table 2: Meta-analysis of the association between PDCD6 rs3756712 $T>G$ and $r$ rs4957014 $T>G$ polymorphisms and cancer risk

\begin{tabular}{|c|c|c|c|c|c|c|c|}
\hline SNP & Genetic model & OR & $95 \% \mathrm{CI}$ & $p$ & Heterogenecity $\mathbf{I}^{2}(\%)$ & $\begin{array}{c}\text { Egger's } \\
\text { test } P\end{array}$ & $\begin{array}{c}\text { Begg's } \\
\text { test } P\end{array}$ \\
\hline \multicolumn{8}{|c|}{ rs 3756712} \\
\hline & TG vs TT & 0.82 & $0.70-0.96$ & 0.01 & 23 & 0.656 & 1.00 \\
\hline & GG vs TT & 0.53 & $0.39-0.72$ & $<0.0001$ & 0 & 0.759 & 1.00 \\
\hline & TG+GG vs TT & 0.76 & $0.66-0.89$ & 0.0004 & 7 & 0.477 & 0.497 \\
\hline & GG vs $\mathrm{TT}+\mathrm{TG}$ & 0.57 & $0.43-0.78$ & 0.0003 & 0 & 0.877 & 0.497 \\
\hline & TG vs $\mathrm{TT}+\mathrm{GG}$ & 0.88 & $0.75-1.02$ & 0.09 & 28 & 0.729 & 0.497 \\
\hline & G vs T & 0.76 & $0.67-0.86$ & $<0.00001$ & 0 & 0.448 & 1.00 \\
\hline \multicolumn{8}{|c|}{ rs4957014 } \\
\hline & TG vs TT & 0.99 & $0.70-1.40$ & 0.97 & 79 & 0.661 & 0.497 \\
\hline & GG vs TT & 1.12 & $0.67-1.89$ & 0.66 & 77 & 0.190 & 0.174 \\
\hline & $\mathrm{TG}+\mathrm{GG}$ vs TT & 1.02 & $0.73-1.44$ & 0.90 & 81 & 0.865 & 0.497 \\
\hline & GG vs $\mathrm{TT}+\mathrm{TG}$ & 1.12 & $0.70-1.78$ & 0.64 & 74 & 0.018 & 0.042 \\
\hline & TG vs $\mathrm{TT}+\mathrm{GG}$ & 0.96 & $0.71-1.31$ & 0.82 & 77 & 0.570 & 1.00 \\
\hline & G vs T & 1.04 & $0.80-1.34$ & 0.79 & 81 & 0.373 & 0.174 \\
\hline
\end{tabular}

cancer. As shown in Figure 3 and Table 2, the results showed that $P D C D 6$ rs $3756712 \mathrm{~T}>\mathrm{G}$ polymorphism was significantly associated with decreased risk of cancer under codominant $(\mathrm{OR}=0.82,95 \% \mathrm{CI}=0.70-0.96$, $p=0.01$, TG vs TT; OR $=0.53,95 \% \mathrm{CI}=0.39-0.72$, $p<0.0001$, GG vs TT), dominant $(\mathrm{OR}=0.76,95 \% \mathrm{CI}=$ $0.66-0.89, p=0.0004, \mathrm{TG}+\mathrm{GG}$ vs TT), recessive $(\mathrm{OR}=$ $0.57,95 \% \mathrm{CI}=0.43-0.78, p=0.0003, \mathrm{GG}$ vs $\mathrm{TT}+\mathrm{TG})$, and allele $(\mathrm{OR}=0.76,95 \% \mathrm{CI}=0.67-0.86, p<0.00001$,
G vs $\mathrm{T}$ ) genetic model. Regarding rs4957014 $\mathrm{T}>\mathrm{G}$ polymorphism of $P D C D 6$, the finding did not support an association between rs4957014 $\mathrm{T}>\mathrm{G}$ polymorphism and cancer risk (Figure 4 and Table 2).

\section{Heterogeneity and publication bias}

Heterogeneity of the included studies concerning each polymorphism is shown in Table 2. A funnel plot was 


\section{PDCD6 rs3756712}

A

\begin{tabular}{|c|c|c|c|c|c|c|c|}
\hline \multirow[b]{2}{*}{ Study or Subgroup } & \multicolumn{2}{|c|}{ Experimental } & \multicolumn{2}{|c|}{ Control } & \multicolumn{3}{|c|}{ Odds Ratio } \\
\hline & Events & Total & Events & Total & Weight & $\mathrm{M}-\mathrm{H}$, Fixed, $95 \% \mathrm{Cl}$ & Year \\
\hline He 2012 & 120 & 288 & 111 & 279 & $19.0 \%$ & $1.08[0.77,1.51]$ & 2012 \\
\hline Zhou & 101 & 315 & 183 & 462 & $29.2 \%$ & $3,0.97]$ & 2014 \\
\hline Zhou 2015 & 109 & 311 & 195 & 493 & $28.4 \%$ & $0.82[0.61,1.11]$ & 2015 \\
\hline Yuan 2017 & 70 & 22 & 184 & 474 & $23.4 \%$ & $0.72[0.51,1.01]$ & 2017 \\
\hline Total & & 1137 & & 1708 & $100.0 \%$ & $0.82[0.70,0.96]$ & \\
\hline $\begin{array}{l}\text { Total events } \\
\text { Heterogeneity. Cl } \\
\text { Test for overall } \mathrm{e}\end{array}$ & 400 & & $\begin{array}{c}673 \\
277 ; 1\end{array}$ & & & & \\
\hline
\end{tabular}

Odds Ratio

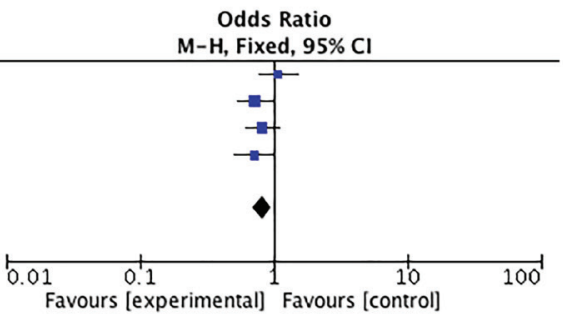

B

Experimental Control Odds Ratio Study or Subgroup Events Total Events Total Weight $\mathrm{M}-\mathrm{H}$, Fixed, $95 \% \mathrm{Cl}$ Year $\begin{array}{llllllll}\text { He } 2012 & 14 & 182 & 27 & 195 & 19.8 \% & 0.52[0.26,1.02] & 2012\end{array}$ $\begin{array}{lllllllll}\text { Zhou 2014 } & 17 & 231 & 47 & 326 & 29.8 \% & 0.47[0.26,0.84] & 2014\end{array}$ $\begin{array}{llllllll}\text { Zhou } 2015 & 17 & 219 & 48 & 346 & 28.3 \% & 0.52[0.29,0.93] & 2015\end{array}$

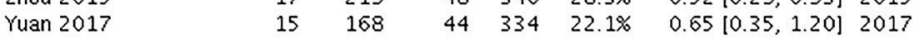
$\begin{array}{lllll}\text { Total }(95 \% \mathrm{Cl}) & 800 & 1201 & 100.0 \% & 0.53[0.39,0.72]\end{array}$ $\begin{array}{lcc}\text { Total events } & 63 & 165 \\ \text { Heterogeneity. } C \mathrm{Ch}^{2}=0.55, \mathrm{df}=3(\mathrm{P}=0.91) ; \mathrm{I}^{2}=0 \%\end{array}$ Test for overall effect: $Z=4.02(P<0.0001)$

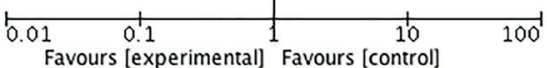

C

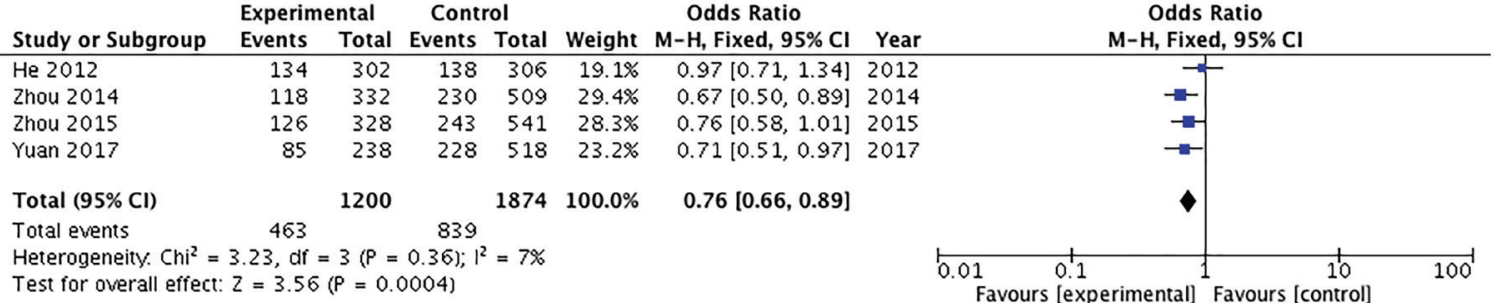

D

\begin{tabular}{|c|c|c|c|c|c|c|}
\hline \multirow[b]{2}{*}{ Study or Subgroup } & \multicolumn{2}{|c|}{ Experimental } & \multicolumn{2}{|c|}{ Control } & \multirow[b]{2}{*}{ Weight } & \multirow{2}{*}{$\begin{array}{l}\text { Odds Ratio } \\
\text { M-H, Fixed, 95\% CI }\end{array}$} \\
\hline & Events & & & Total & & \\
\hline He 2012 & 14 & 302 & 27 & 306 & $21.1 \%$ & $0.50[0.26,0.98]$ \\
\hline Zhou 2014 & 17 & 332 & 47 & 509 & $29.1 \%$ & $30,0.94]$ \\
\hline zhou 2 & 17 & 328 & 48 & 541 & $28.4 \%$ & $0.56[0.32,0.99]$ \\
\hline Yuan 2017 & 15 & 238 & 44 & 518 & $21.4 \%$ & $0.72[0.39,1.33]$ \\
\hline Total $(9$ & & 1200 & & 1874 & $100.0 \%$ & $0.57[0.43,0.78]$ \\
\hline Total events & 63 & & 166 & & & \\
\hline Heterogeneity. & o, df & $=3(P=$ & $851 ; 1^{2}$ & $=0 x_{0}$ & & \\
\hline
\end{tabular}

Heterogeneity. Chis $=0.80, \mathrm{dr}=3(\mathrm{P}=0.85) ; \mathrm{l}^{2}=0 \mathrm{x}$ Test ror overa

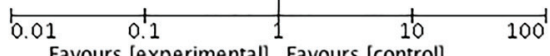

E

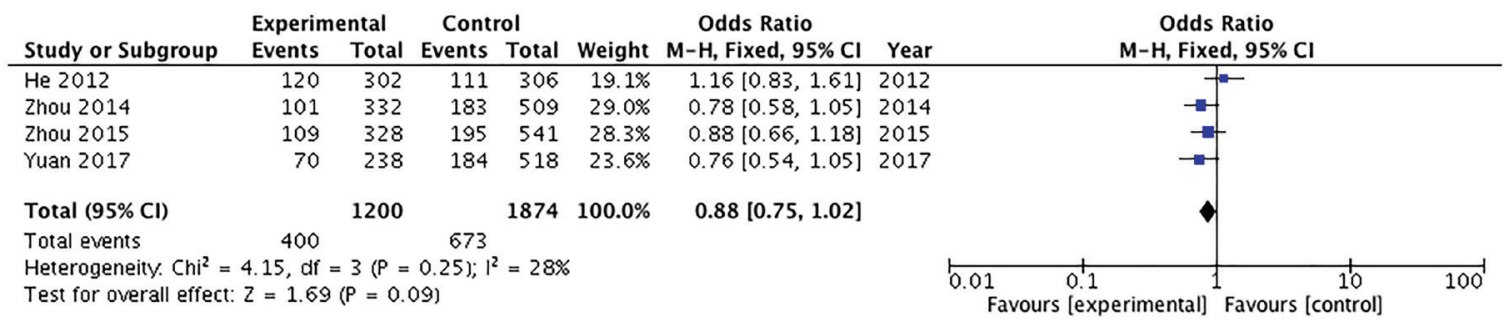

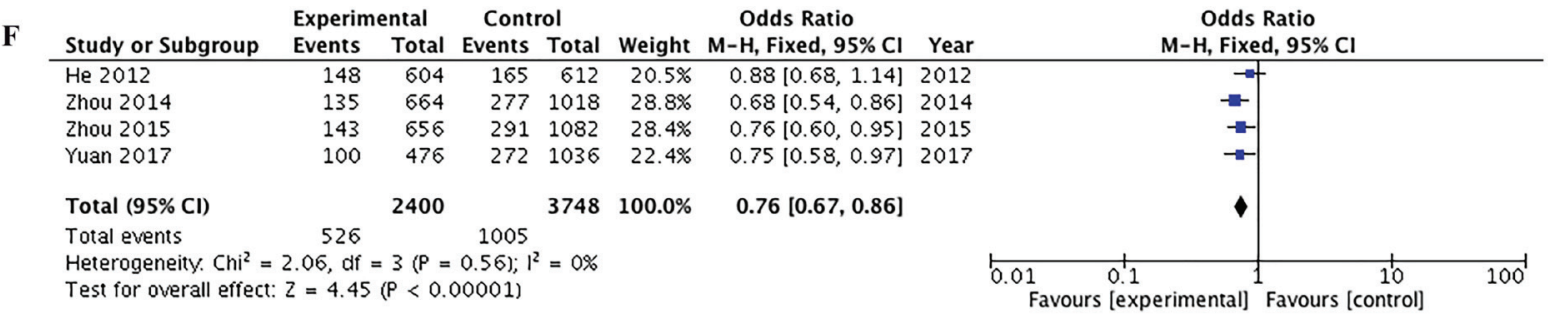

Figure 3: Forest plots of the association between cancer risk and the $r s 3756712 \mathrm{~T}>\mathrm{G}$ polymorphism in the overall study population under the following models. (A) TG vs TT, (B) GG vs TT, (C) TG+GG vs TT, (D) GG vs TT+TG, (E) TG vs $\mathrm{TT}+\mathrm{GG}$, and $(\mathbf{F}) \mathrm{G} v s \mathrm{~T}$. 


\section{PDCD6 rs4957014}

A

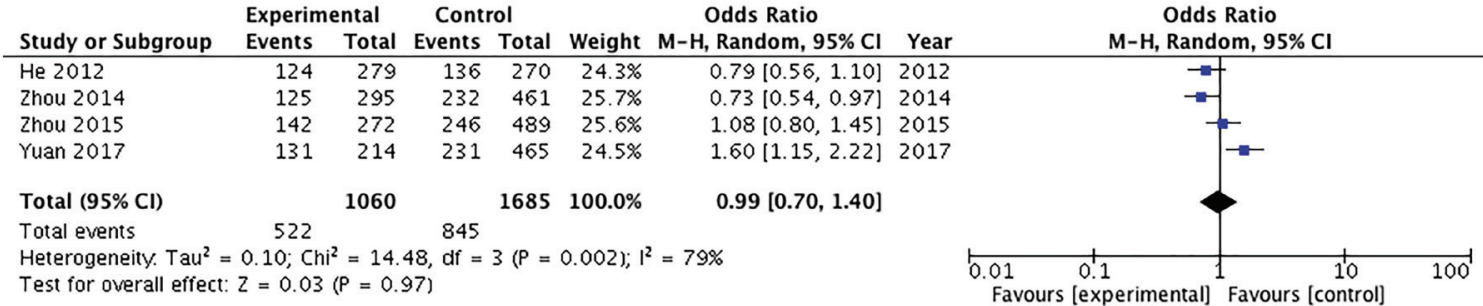

B

\begin{tabular}{llllll} 
Study or Subgroup & \multicolumn{2}{l}{ Experimental Control } & \multicolumn{2}{c}{ Odds Ratio } \\
Events & Total Events Total Weight $\mathrm{M}-\mathrm{H}$, Random, $95 \% \mathrm{Cl}$ Yea
\end{tabular}

$\begin{array}{llllllll}\text { He } 2012 & 23 & 178 & 36 & 170 & 23.5 \% & 0.55[0.31,0.98] 2012\end{array}$

$\begin{array}{llllllll}\text { Zhou } 2014 & 37 & 207 & 48 & 277 & 25.8 \% & 1.04[0.65,1.67] 2014\end{array}$

$\begin{array}{llllllll}\text { Zhou } 2015 & 56 & 186 & 52 & 295 & 26.7 \% & 2.01[1.31,3.11] 2015\end{array}$

$\begin{array}{llllllll}\text { Yuan } 2017 & 24 & 107 & 53 & 287 & 24.1 \% & 1.28[0.74,2.20] & 2017\end{array}$

Total $(95 \% \mathrm{Cl})$

Total events

$678 \quad 1029 \quad 100.0 \%$

$1.12[0.67,1.89]$

Heterogeneity. $\mathrm{Tau}^{2}=0.22 ; \mathrm{Chi}^{2}=12.96, \mathrm{df}=3(\mathrm{P}=0.005) ; \mathrm{I}^{2}=77 \%$

Test for overall effect: $Z=0.44(P=0.66)$

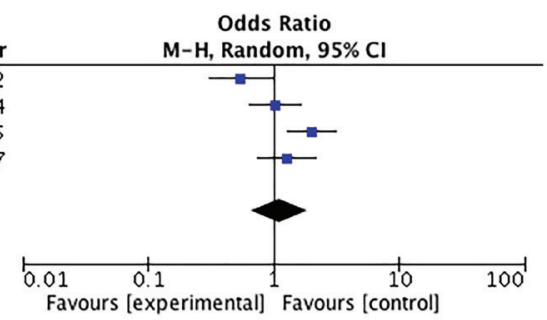

C

Experimental Control Odds Ratio

Study or Subgroup Events Total Events Total Weight M-H, Random, 95\% Cl Year $\begin{array}{llllllll}\text { He } 2012 & 147 & 302 & 172 & 306 & 24.3 \% & 0.74[0.54,1.02] 2012\end{array}$ $\begin{array}{llllllll}\text { Zhou } 2014 & 162 & 332 & 280 & 509 & 25.7 \% & 0.78[0.59,1.03] & 2014\end{array}$ $\begin{array}{llllllll}\text { Zhou } 2015 & 198 & 328 & 298 & 541 & 25.6 \% & 1.24[0.94,1.64] 2015\end{array}$

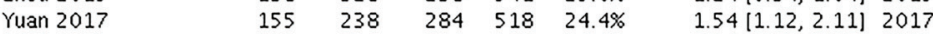
$\left.\begin{array}{lllll}\text { Total }(95 \% \mathrm{Cl}) & 1200 & 1874 & 100.0 \% & 1.02\end{array}\right]$ Total events $\quad 662 \quad 1034$ Heterogeneity. $\mathrm{Tau}^{2}=0.10 ; \mathrm{Chi}^{2}=15.89, \mathrm{df}=3(\mathrm{P}=0.001) ; \mathrm{I}^{2}=81 \%$ Test for overall effect: $Z=0.13(P=0.90)$

Random, 95\% Cl

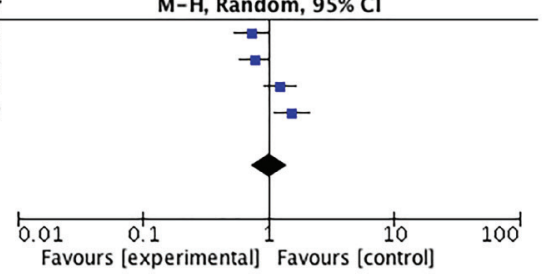

Experimental Control Odds Ratio $\quad$ Odds Ratio

D Study or Subgroup Events Total Events Total Weight $\mathrm{M}-\mathrm{H}, \mathrm{Random}, 95 \% \mathrm{Cl}$ Year \begin{tabular}{llllllrl}
\hline He 2012 & 23 & 302 & 36 & 306 & $23.1 \%$ & $0.62[0.36,1.07] 2012$
\end{tabular} $\begin{array}{llllllll}\text { Zhou 2014 } & 37 & 332 & 48 & 509 & 25.7 \% & 1.20[0.77,1.89] 2014\end{array}$ $\begin{array}{llllllll}\text { Zhou } 2015 & 56 & 328 & 52 & 541 & 27.0 \% & 1.94[1.29,2.90] & 2015\end{array}$

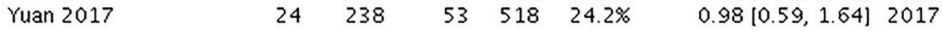
$\begin{array}{lllll}\text { Total }(95 \% \mathrm{Cl}) & 1200 & 1874 & 100.0 \% & 1.12[0.70,1.78\end{array}$

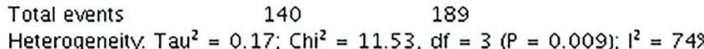
Test for overall effect: $Z=0.47(P=0.64)$

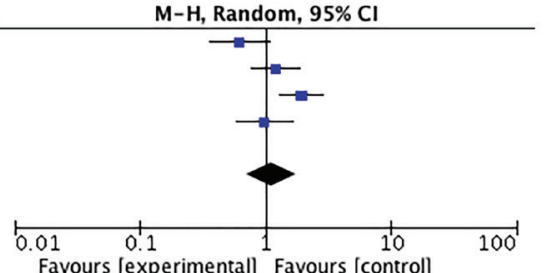

\begin{tabular}{lllll} 
& \multicolumn{2}{l}{ Experimental Control } & \multicolumn{2}{c}{ Odds Ratio } \\
E Study or Subgroup & Events Total Events Total Weight $\mathrm{M}-\mathrm{H}$, Random, $95 \% \mathrm{Cl}$ Year
\end{tabular}

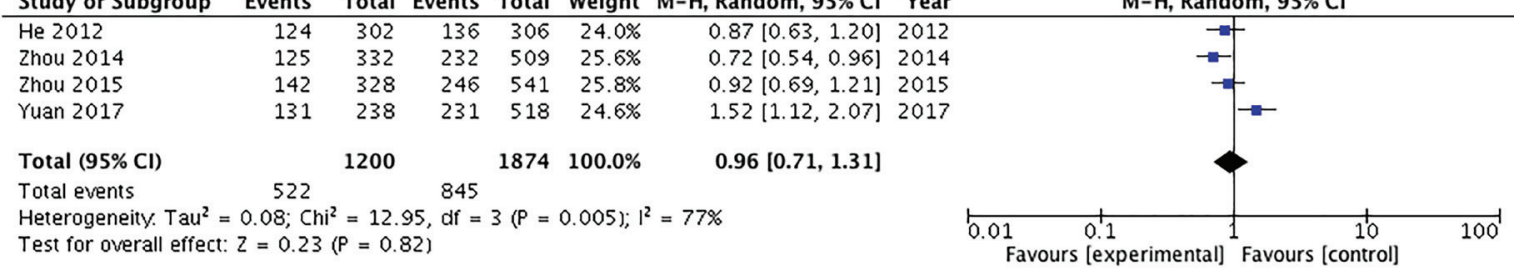

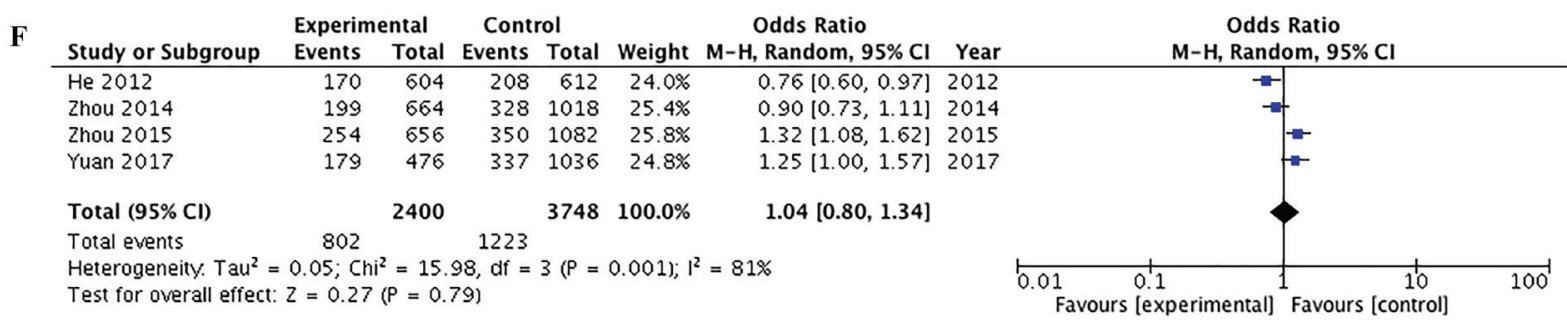

Figure 4: Forest plots of the association between cancer risk and the rs4957014 $\mathrm{T}>\mathrm{G}$ polymorphism in the overall study population under the following models. (A) TG vs TT, (B) GG vs TT, (C) TG+GG vs TT, (D) GG vs TT+TG, (E) TG vs $\mathrm{TT}+\mathrm{GG}$, and $(\mathbf{F}) \mathrm{G} v s \mathrm{~T}$. 
generated as a visual aid to detect risk of publication bias (Figures 5 and 6). Regarding rs3756712 variant, Egger's linear regression analysis suggested no publication bias for this meta-analysis of the codominant, dominant, recessive, overdominanat and allele model (all $P$-values for bias $>0.05)$. For rs4957014 polymorphism, the findings indicated that the publication bias exist only for recessive model (Table 2).

\section{Sensitivity analysis}

Sensitivity analysis was done using the method of eliminating studies one by one to verify whether our results were influenced by each included study. For rs3756712 variant, the pooled ORs were not considerably altered except in codominant heterozygous model (TG vs TT) and overdominant (TG vs TT $+\mathrm{GG}$ ) model (Figure 7). Regarding rs4957014 variant, the pooled ORs altered only in overdominant model (Figure 8). Therefore, the results confirmed that the present meta-analysis was relatively stable and reliable.

\section{DISCUSSION}

PDCD6, a proapoptotic protein, is a $\mathrm{Ca}^{2+}$ binding protein of the EF-hand type belonging to the subfamily
A

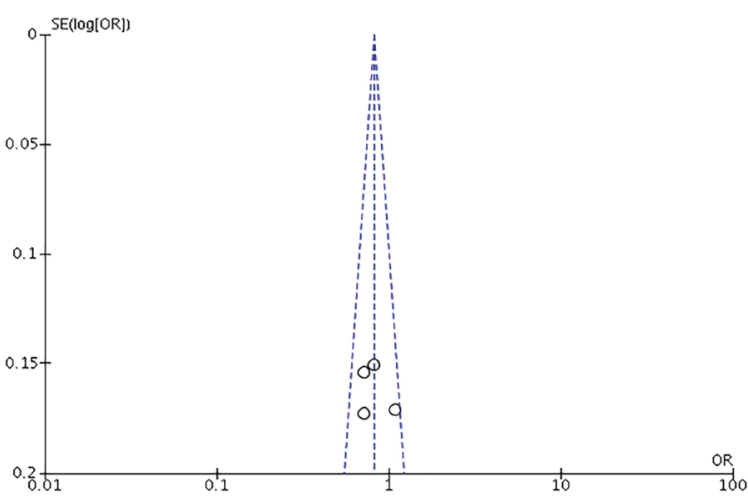

C

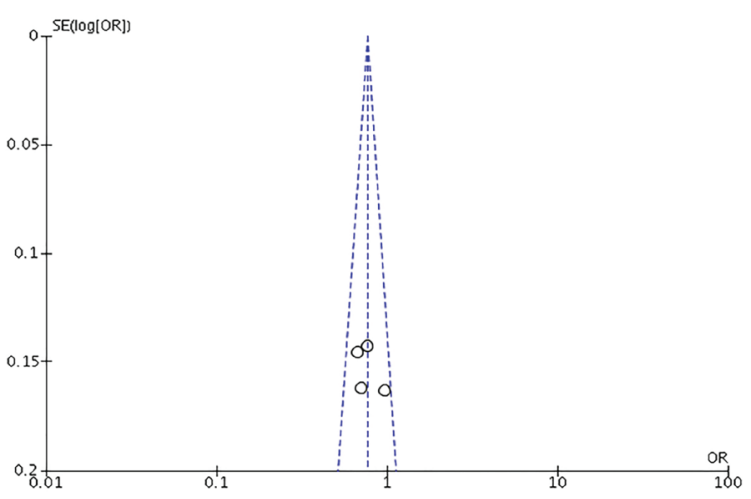

$\mathbf{E}$

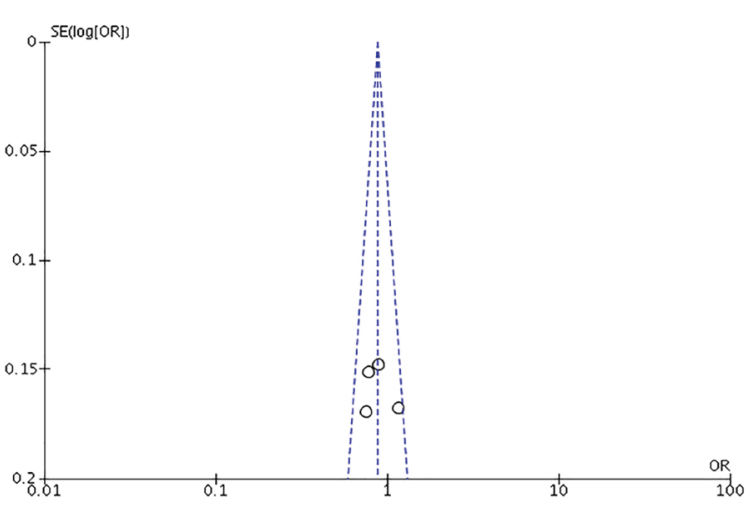

B

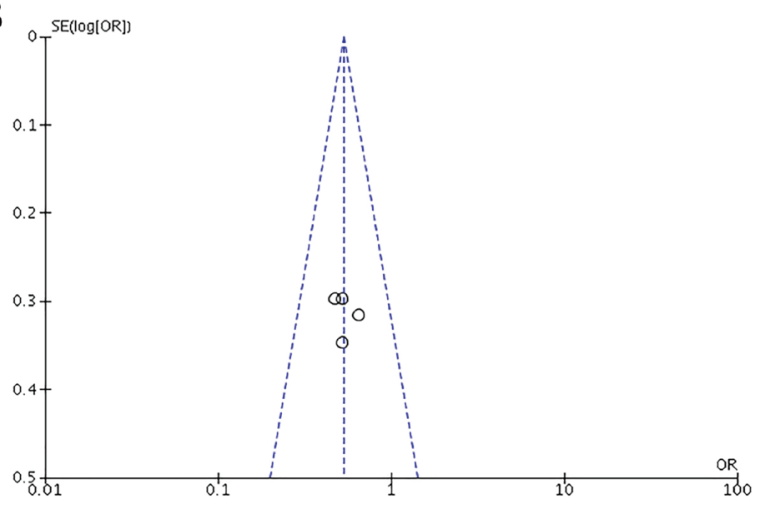

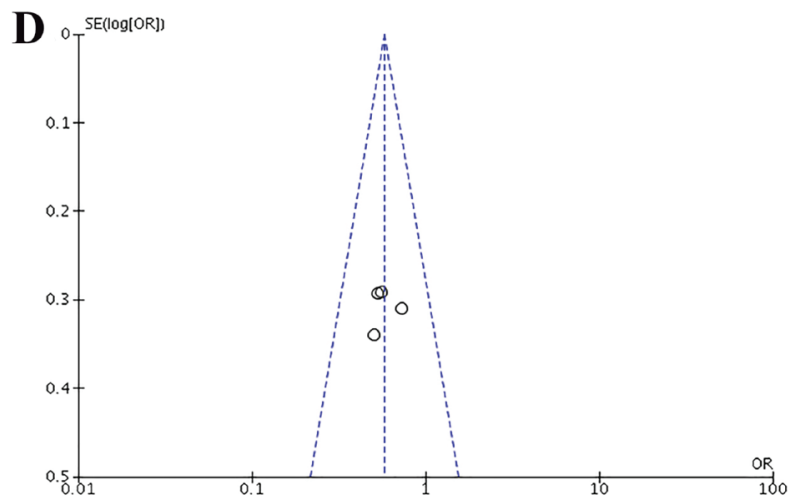

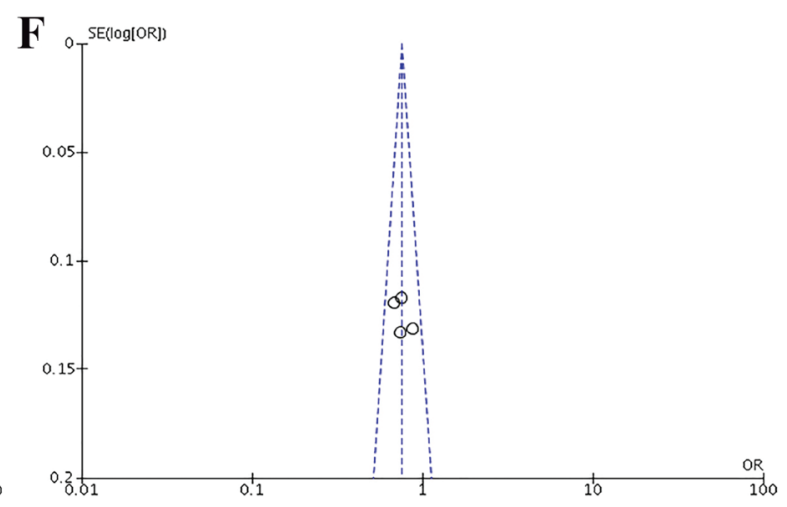

Figure 5: Funnel plots of the association between cancer risk and the $\operatorname{rs3756712} \mathrm{T}>\mathrm{G}$ polymorphism in the overall study population under the following models. (A) TG vs TT, (B) GG vs TT, (C) TG+GG vs TT, (D) GG vs TT+TG, (E) TG vs $\mathrm{TT}+\mathrm{GG}$, and (F) G vs T. 
of penta-EF-hand (PEF) protein that is required for the induction of apoptosis by a variety of stimuli $[35,20]$. Binding of $\mathrm{Ca}^{2+}$ to PDCD6 induces a conformational change [34], which enables the interaction with several proteins, including ALG-2-interacting protein $\mathrm{X}$ (ALIX) [36], Sec31A [39, 16], and annexin A11 [28, 29]. Several lines of evidence suggest that interacting partner of PDCD6 is ALIX/AIP1, an adaptor protein, which has been implicated in apoptotic signaling $[23,13]$.

The pathogenesis of carcinogenesis involves environmental factors, molecular signaling pathways, and host genetic factors $[1,6]$. Since single nucleotide polymorphism (SNP) is the main cause of human genetic
A

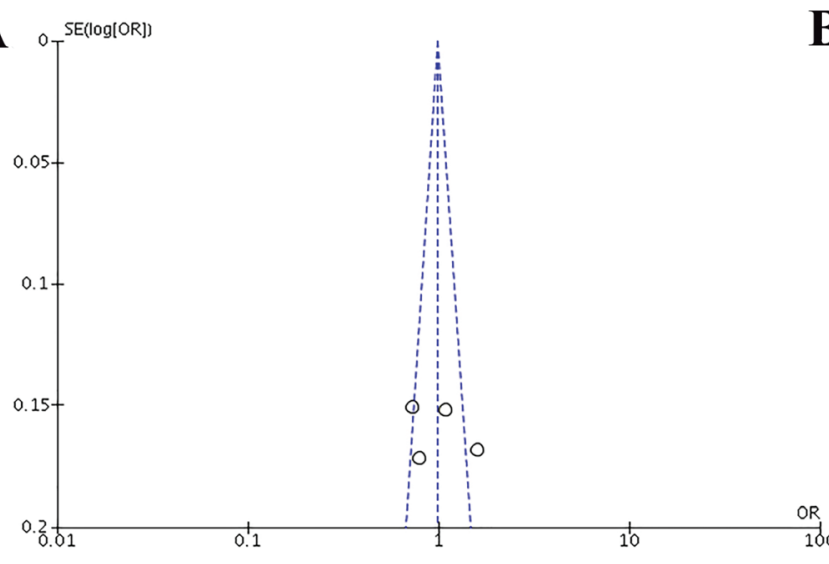

B

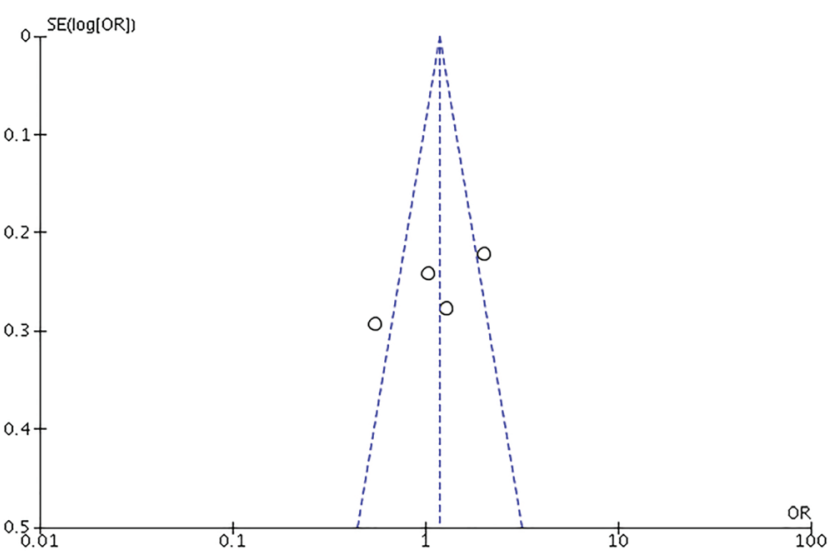

C

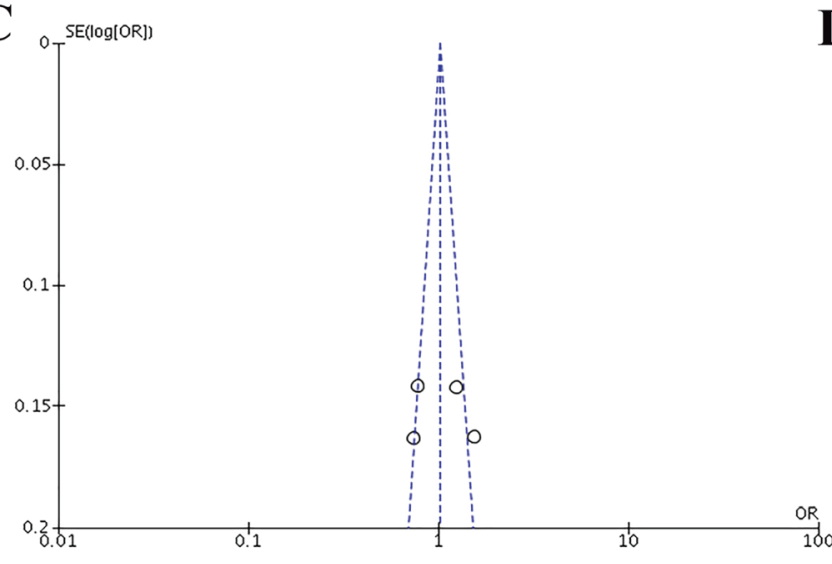

D

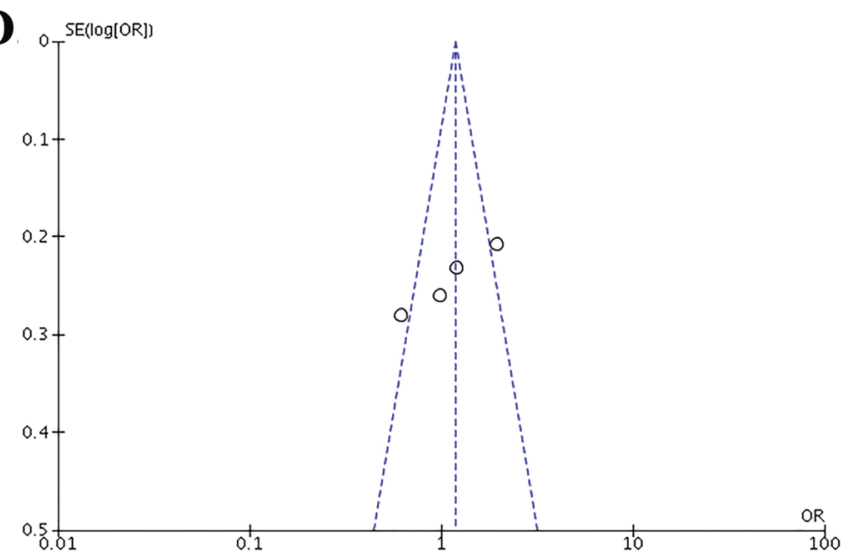

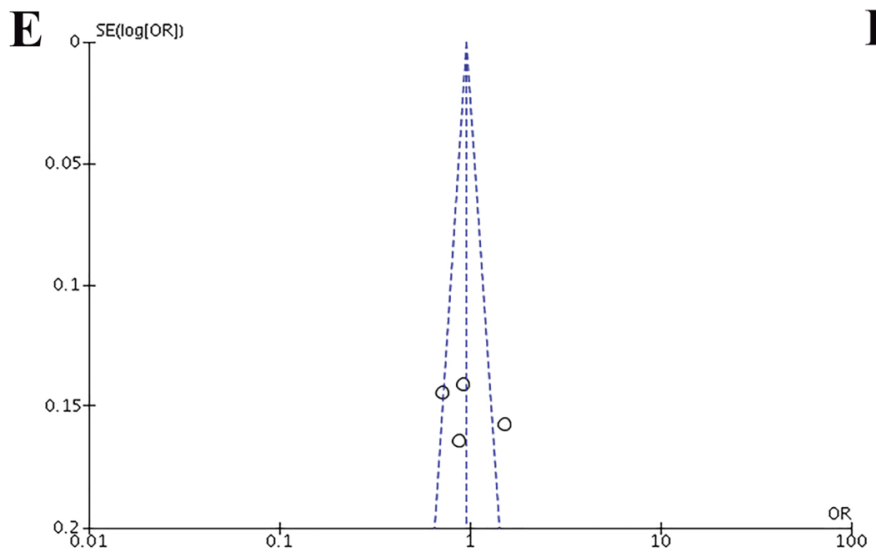

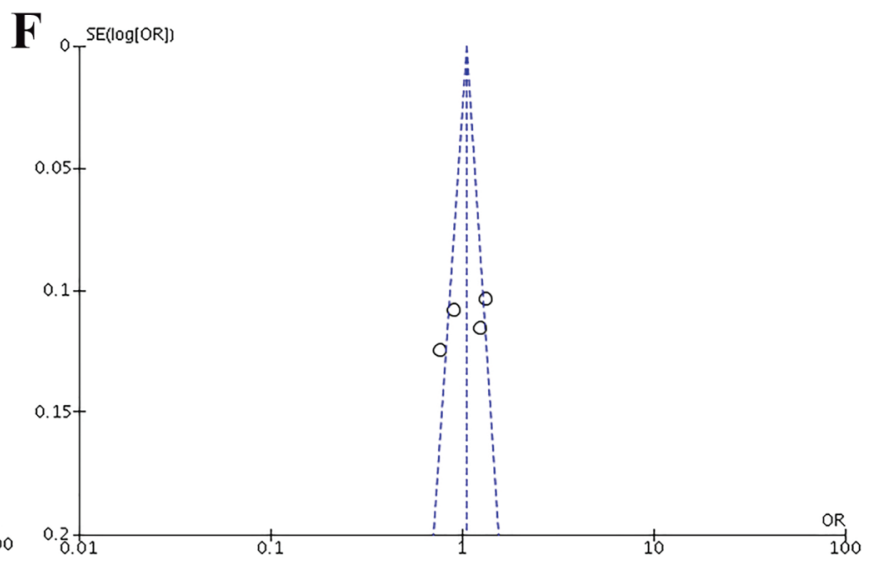

Figure 6: Funnel plots of the association between cancer risk and the rs4957014 $\mathrm{T}>\mathrm{G}$ polymorphism in the overall study population under the following models. (A) TG vs TT, (B) GG vs TT, (C) TG+GG vs TT, (D) GG vs TT+TG, (E) TG vs $\mathrm{TT}+\mathrm{GG}$, and (F) G vs T. 
variation, the connection between SNPs and individual risk of cancer has drawn considerable attention [27, 8]. As we know, limited polymorphisms have been reported about PDCD6 gene. Several investigations have been done to find the possible association between two tag SNPs of PDCD6, rs3756712 and rs4957014 polymorphisms, and various cancer risk [45, 9, 44, 42]. Zhou et al. [45] reported that rs3756712 and rs4957014 polymorphisms of PDCD6 significantly decreased the risk of bladder cancer. He et al. [9] have found no significant association between PDCD6 rs3756712 variant and risk of Non-small cell lung cancer

A

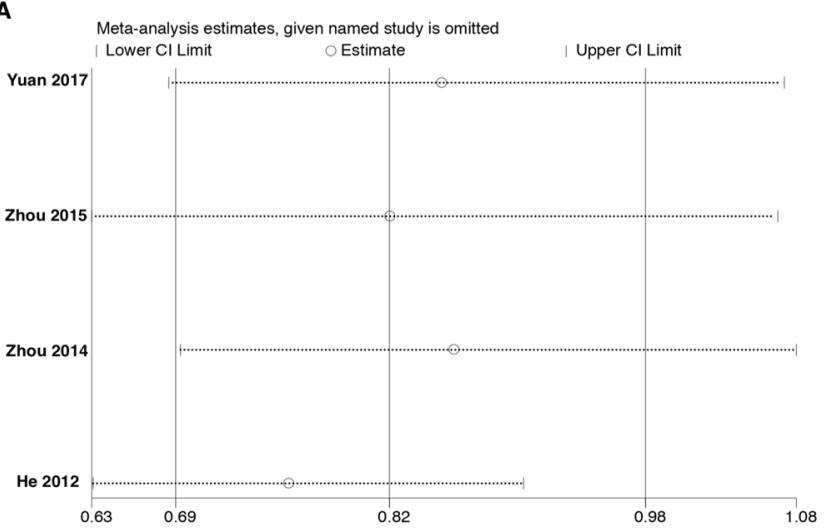

C

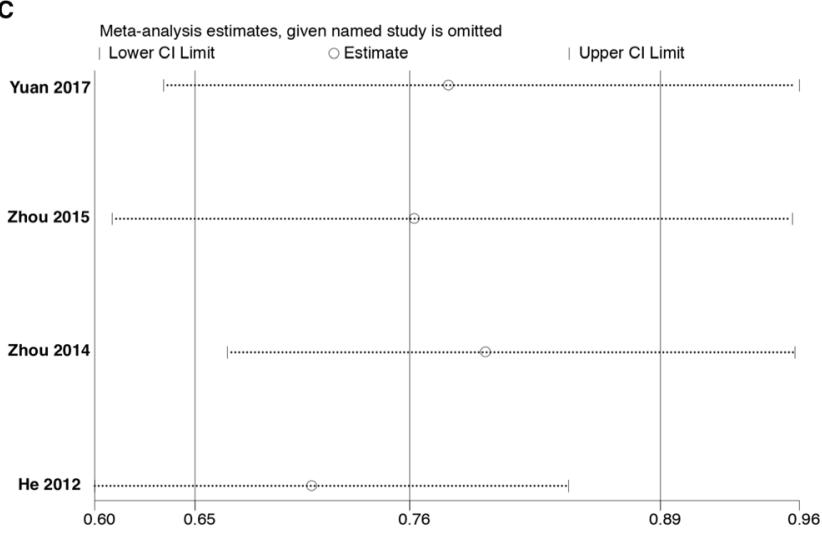

$\mathbf{E}$

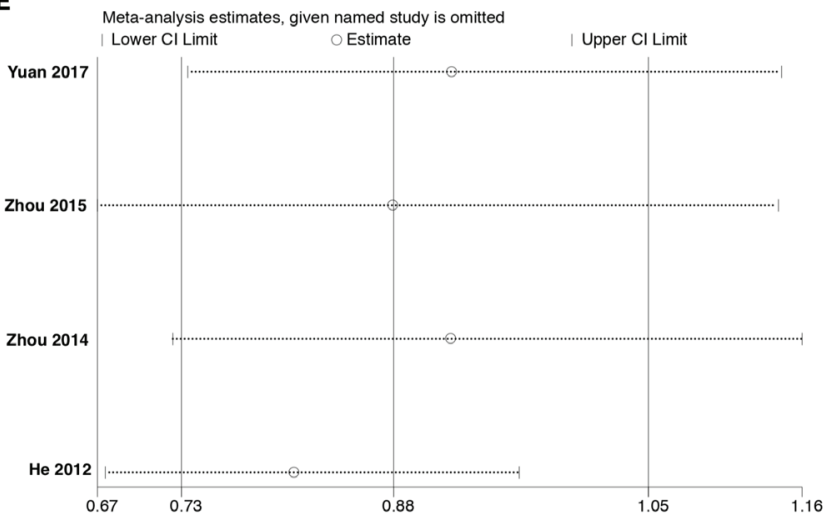

(NSCLC). Their findings proposed that rs4957014 variant of PDCD6 significantly decreased the risk of NSCLC. On the other hand, it has been revealed that rs3756712 and rs4957014 polymorphisms of PDCD6 significantly increased the risk of cervical squamous cell carcinoma (CSCC) [44]. Recently, Yuan et al. [42] investigated the association between rs3756712 and rs4957014 polymorphisms of PDCD6 and risk of CSCC. Their findings suggested that both of the variants significantly increased the risk of CSCC.
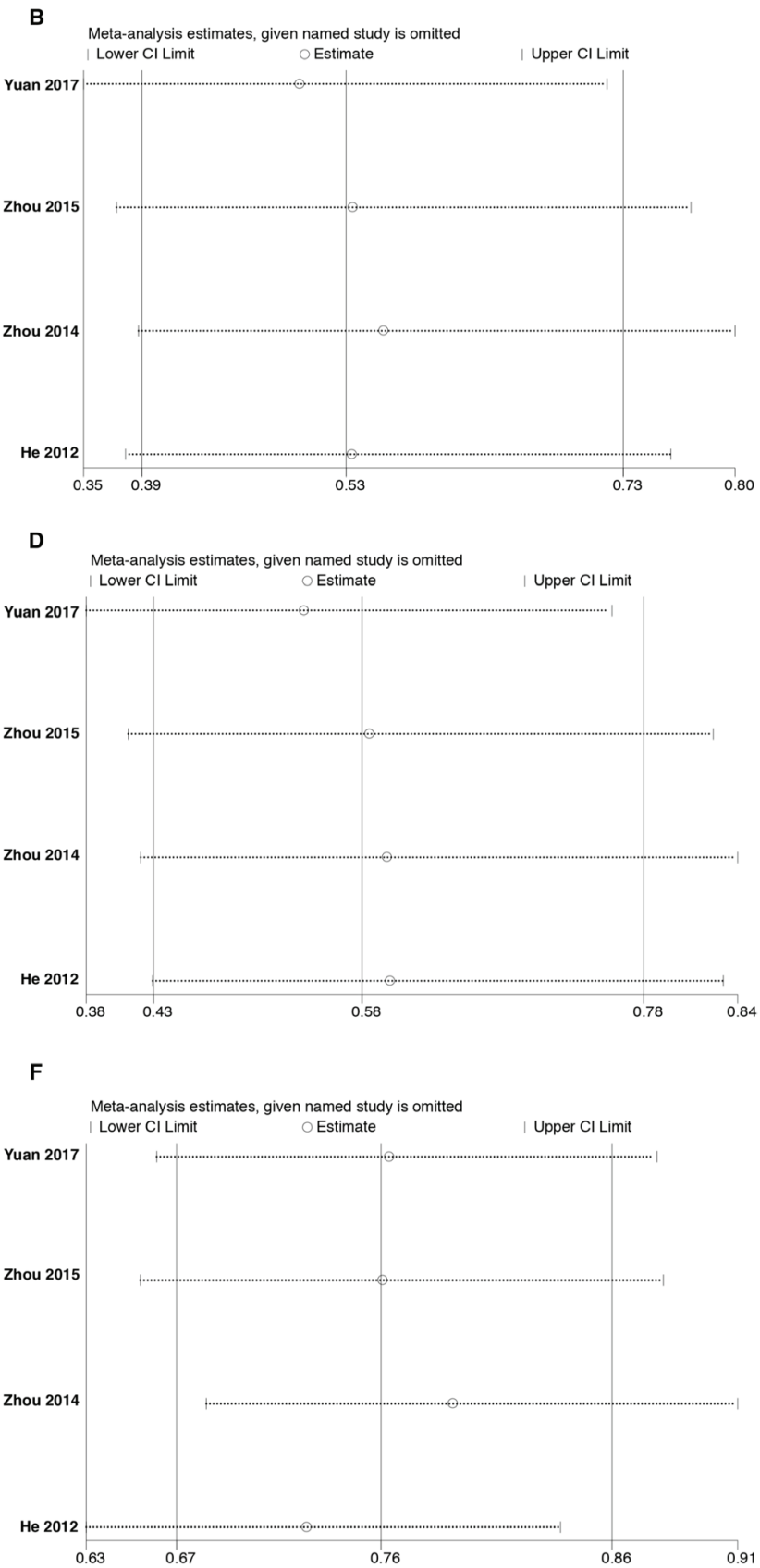

Figure 7: Sensitivity analyses for studies on $P D C D 6$ rs3756712 T>G using different genetic models. (A) TG vs TT, (B) GG vs TT, (C) TG+GG vs TT, (D) GG vs TT+TG, (E) TG vs TT+GG, and (F) G vs T. 
Due to contrasting findings about PDCD6 polymorphism in certain types of cancers, the present meta-analysis was performed to evaluate the impact of two SNPs of $P D C D 6$ on cancer risk. To our knowledge, this is the first meta-analysis evaluating the impact of $P D C D 6$ polymorphisms on cancer. The attained results suggest that the PDCD6 rs $3756712 \mathrm{~T}>\mathrm{G}$ polymorphism significantly decreased the risk of cancer under codominant, dominant, recessive, and allele genetic model. The findings did not support an association between rs4957014 $\mathrm{T}>\mathrm{G}$ polymorphism of $P D C D 6$ and cancer risk.

In conclusion, to our knowledge, this fist the present study suggested that there is an association between the PDCD6 rs3756712 $\mathrm{T}>\mathrm{G}$ polymorphism and cancer. The rs3756712 $\mathrm{T}>\mathrm{G}$ variant may be a potential marker for cancer. Further well-designed case-control studies with a larger sample size and different ethnicities should be done to confirm the findings.
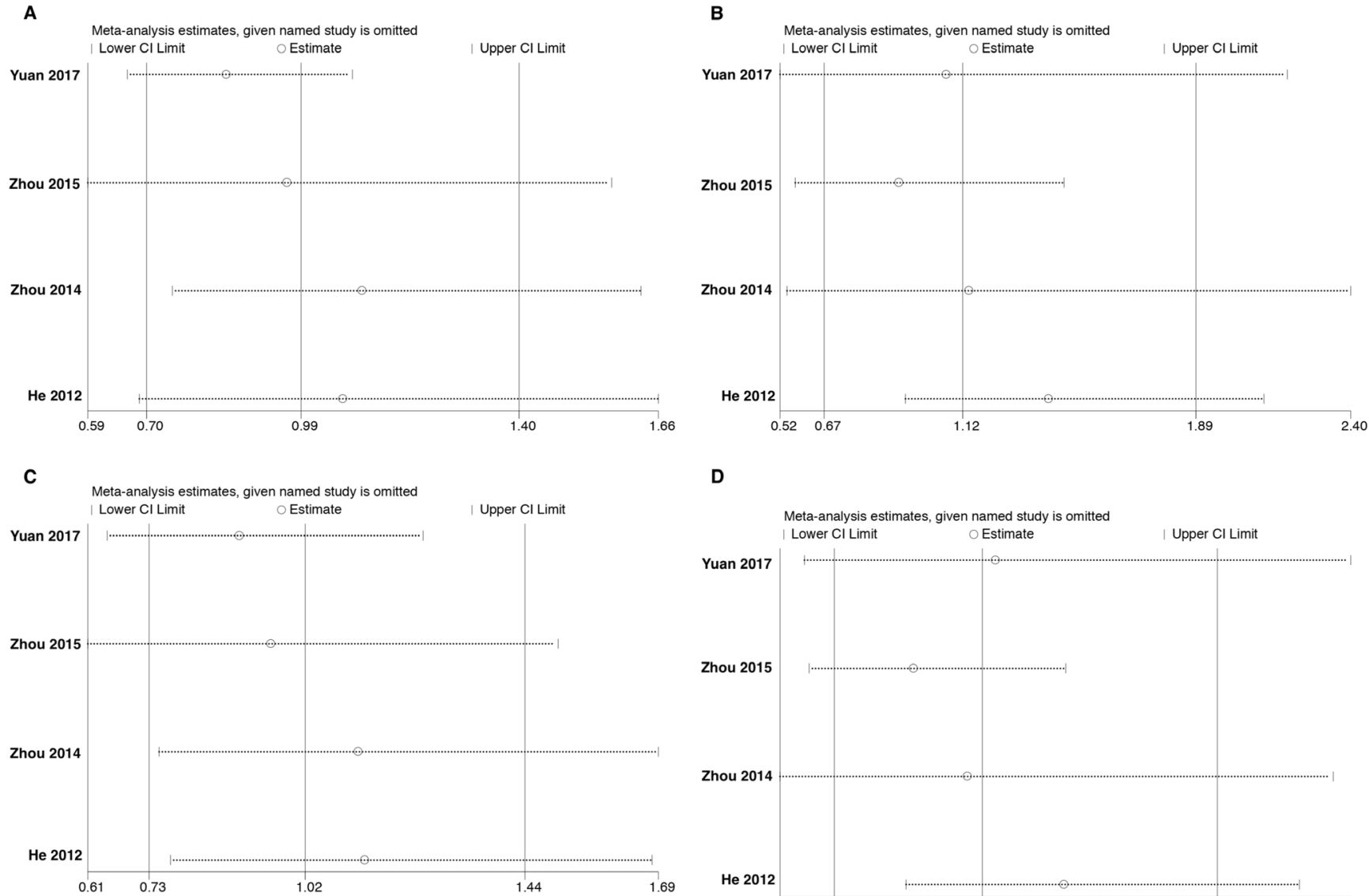

D
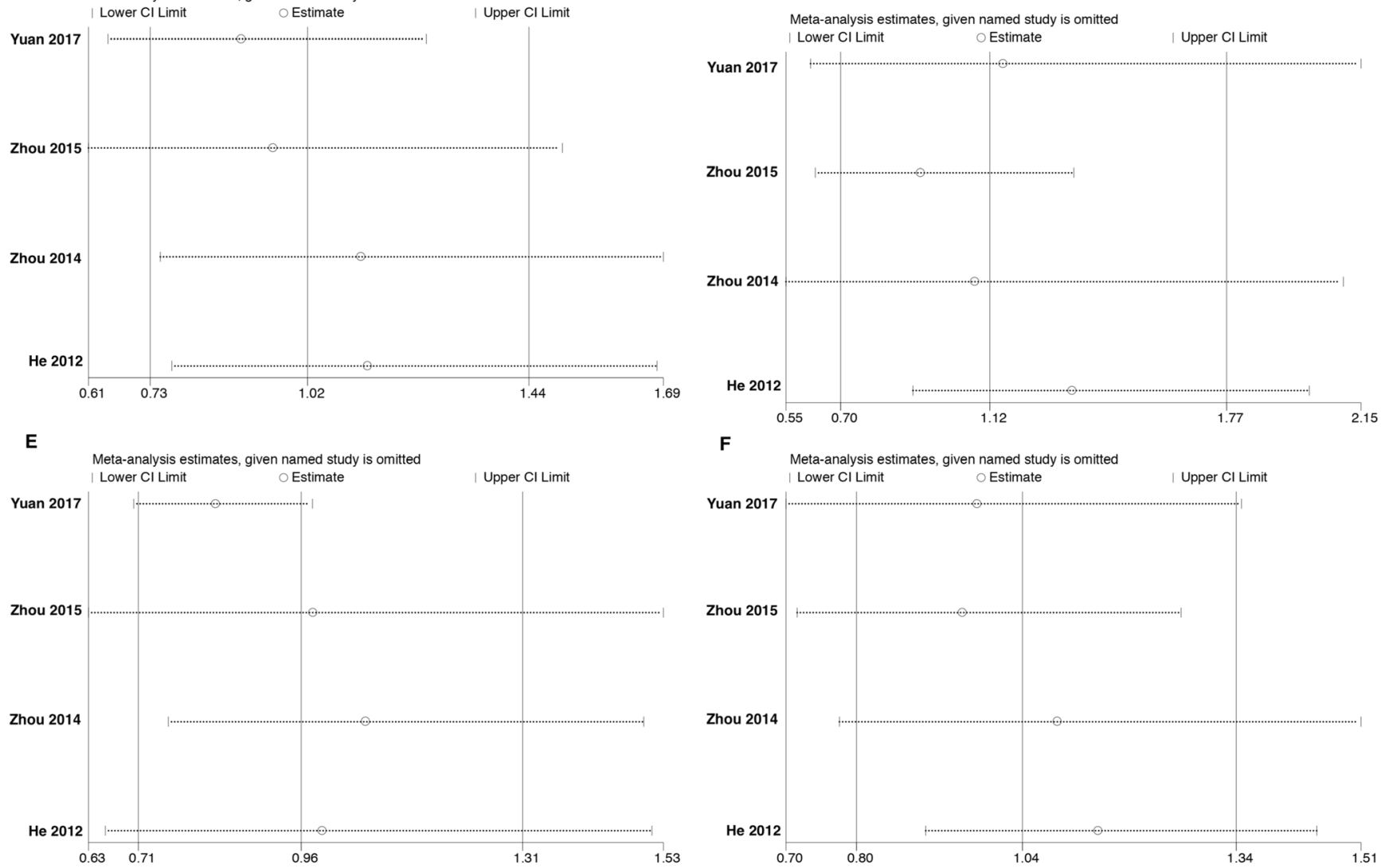

Figure 8: Sensitivity analyses for studies on $P D C D 6$ rs4957014 $\mathbf{T}>\mathbf{G}$ using different genetic models. (A) TG vs TT, (B) GG vs TT, (C) TG+GG vs TT, (D) GG vs TT+TG, (E) TG vs TT+GG, and (F) G vs T. 


\section{Abbreviations}

ALG-2: apoptosis-linked gene-2; AIP1: ALG-2interacting protein 1; ALIX: ALG-2-interacting protein X; CSCC: cervical squamous cell carcinoma; CI: confidence interval; HWE: Hardy-Weinberg equilibrium; NSCLC: non-small cell lung cancer; OR: odds ratio; PEF: pentaEF-hand; PDCD6: Programmed cell death protein 6; RevMan: Review Manager; SNP: since single nucleotide polymorphism.

\section{CONFLICTS OF INTEREST}

The authors have declared that no competing interests exist.

\section{FUNDING}

SG was supported by CHRIM operating grant, Health Science Foundation general operating grant and Research Manitoba New Investigator operating grant. MJŁ kindly acknowledges the support from NCN grant \#: 2016/21/B/NZ1/02812, and by LE STUDIUM Institute for Advanced Studies (region Centre-Val de Loire, France) through its Smart Loire Valley General Program, cofunded by the Marie Sklodowska-Curie Actions, grant \# 665790 .

\section{REFERENCES}

1. Alizadeh J, Zeki AA, Mirzaei N, Tewary S, Rezaei Moghadam A, Glogowska A, Nagakannan P, Eftekharpour E, Wiechec E, Gordon JW, Xu FY, Field JT, Yoneda KY, et al. Mevalonate Cascade Inhibition by Simvastatin Induces the Intrinsic Apoptosis Pathway via Depletion of Isoprenoids in Tumor Cells. Sci Rep. 2017; 7:44841.

2. Egger M, Davey Smith G, Schneider M, Minder C. Bias in meta-analysis detected by a simple, graphical test. BMJ. 1997; 315:629-34.

3. Ferlay J, Soerjomataram I, Dikshit R, Eser S, Mathers C, Rebelo M, Parkin DM, Forman D, Bray F. Cancer incidence and mortality worldwide: sources, methods and major patterns in GLOBOCAN 2012. Int J Cancer. 2015; 136: E359-86.

4. Foulkes WD. Inherited susceptibility to common cancers. N Engl J Med. 2008; 359:2143-53.

5. Ghavami S, Hashemi M, Ande SR, Yeganeh B, Xiao W, Eshraghi M, Bus CJ, Kadkhoda K, Wiechec E, Halayko AJ, Los M. Apoptosis and cancer: mutations within caspase genes. J Med Genet. 2009; 46:497-510.

6. Ghavami S, Shojaei S, Yeganeh B, Ande SR, Jangamreddy JR, Mehrpour M, Christoffersson J, Chaabane W, Moghadam AR, Kashani HH, Hashemi M, Owji AA, Los MJ. Autophagy and apoptosis dysfunction in neurodegenerative disorders. Prog Neurobiol. 2014; 112:24-49.

7. Hashemi M, Kroczak TJ. Apoptosis and autoimmune disease. Curr Med Chem Anti Inflamm Anti Allergy Agents. 2005; 4:429-37.

8. Hassanzarei S, Hashemi M, Sattarifard H, Hashemi SM, Bahari G, Ghavami S. Genetic polymorphisms of HOTAIR gene are associated with the risk of breast cancer in a sample of southeast Iranian population. Tumour Biol. 2017; 39:1010428317727539.

9. He YQ, Zhou B, Shi SQ, Zhang L, Li WM. Genetic variation in PDCD6 and susceptibility to lung cancer. Asian Pac J Cancer Prev. 2012; 13:4689-93.

10. Hoj BR, la Cour JM, Mollerup J, Berchtold MW. ALG-2 knockdown in HeLa cells results in G2/M cell cycle phase accumulation and cell death. Biochem Biophys Res Commun. 2009; 378:145-8.

11. Hombach-Klonisch S, Mehrpour M, Shojaei S, Harlos C, Pitz M, Hamai A, Siemianowicz K, Likus W, Wiechec E, Toyota BD, Hoshyar R, Seyfoori A, Sepehri Z, et al. Glioblastoma and chemoresistance to alkylating agents: Involvement of apoptosis, autophagy, and unfolded protein response. Pharmacol Ther. 2018; 184:13-41.

12. Jung YS, Kim KS, Kim KD, Lim JS, Kim JW, Kim E. Apoptosis-linked gene 2 binds to the death domain of Fas and dissociates from Fas during Fas-mediated apoptosis in Jurkat cells. Biochem Biophys Res Commun. 2001; 288:420-6.

13. Kaul Z, Chakrabarti O. Tumor susceptibility gene 101 regulates predisposition to apoptosis via ESCRT machinery accessory proteins. Mol Biol Cell. 2017; 28:2106-22.

14. Kitaura Y, Matsumoto S, Satoh H, Hitomi K, Maki M. Peflin and ALG-2, members of the penta-EF-hand protein family, form a heterodimer that dissociates in a $\mathrm{Ca} 2+-$ dependent manner. J Biol Chem. 2001; 276:14053-8.

15. la Cour JM, Hoj BR, Mollerup J, Simon R, Sauter G, Berchtold MW. The apoptosis linked gene ALG-2 is dysregulated in tumors of various origin and contributes to cancer cell viability. Mol Oncol. 2008; 1:431-9.

16. la Cour JM, Mollerup J, Berchtold MW. ALG-2 oscillates in subcellular localization, unitemporally with calcium oscillations. Biochem Biophys Res Commun. 2007; 353:1063-7.

17. la Cour JM, Mollerup J, Winding P, Tarabykina S, Sehested M, Berchtold MW. Up-regulation of ALG-2 in hepatomas and lung cancer tissue. Am J Pathol. 2003; 163:81-9.

18. Mahul-Mellier AL, Hemming FJ, Blot B, Fraboulet S, Sadoul R. Alix, making a link between apoptosis-linked gene-2, the endosomal sorting complexes required for transport, and neuronal death in vivo. J Neurosci. 2006; 26:542-9.

19. Mahul-Mellier AL, Strappazzon F, Petiot A, ChatellardCausse C, Torch S, Blot B, Freeman K, Kuhn L, Garin J, 
Verna JM, Fraboulet S, Sadoul R. Alix and ALG-2 are involved in tumor necrosis factor receptor 1-induced cell death. J Biol Chem. 2008; 283:34954-65.

20. Maki M, Narayana SV, Hitomi K. A growing family of the Ca2+-binding proteins with five EF-hand motifs. Biochem J. 1997; 328:718-20.

21. Missotten M, Nichols A, Rieger K, Sadoul R. Alix, a novel mouse protein undergoing calcium-dependent interaction with the apoptosis-linked-gene 2 (ALG-2) protein. Cell Death Differ. 1999; 6:124-9.

22. Mokarram P, Albokashy M, Zarghooni M, Moosavi MA, Sepehri Z, Chen QM, Hudecki A, Sargazi A, Alizadeh J, Moghadam AR, Hashemi M, Movassagh H, Klonisch T, et al. New frontiers in the treatment of colorectal cancer: Autophagy and the unfolded protein response as promising targets. Autophagy. 2017; 13:781-819.

23. Odorizzi G. The multiple personalities of Alix. J Cell Sci. 2006; 119:3025-32.

24. Qin J, Li D, Zhou Y, Xie S, Du X, Hao Z, Liu R, Liu X, Liu M, Zhou J. Apoptosis-linked gene 2 promotes breast cancer growth and metastasis by regulating the cytoskeleton. Oncotarget. 2017; 8:2745-57. https://doi.org/10.18632/ oncotarget.13740.

25. Rao RV, Poksay KS, Castro-Obregon S, Schilling B, Row RH, del Rio G, Gibson BW, Ellerby HM, Bredesen DE. Molecular components of a cell death pathway activated by endoplasmic reticulum stress. J Biol Chem. 2004; 279:177-87.

26. Rashedi I, Panigrahi S, Ezzati P, Ghavami S, Los M. Autoimmunity and apoptosis - therapeutic implications. Curr Med Chem. 2007; 14:3139-51.

27. Risch N, Merikangas K. The future of genetic studies of complex human diseases. Science. 1996; 273:1516-7.

28. Satoh H, Shibata H, Nakano Y, Kitaura Y, Maki M. ALG-2 interacts with the amino-terminal domain of annexin XI in a $\mathrm{Ca}(2+)$-dependent manner. Biochem Biophys Res Commun. 2002; 291:1166-72.

29. Shibata H, Kanadome T, Sugiura H, Yokoyama T, Yamamuro M, Moss SE, Maki M. A new role for annexin A11 in the early secretory pathway via stabilizing Sec31A protein at the endoplasmic reticulum exit sites (ERES). J Biol Chem. 2015; 290:4981-93.

30. Shibata H, Yamada K, Mizuno T, Yorikawa C, Takahashi H, Satoh H, Kitaura Y, Maki M. The penta-EF-hand protein ALG-2 interacts with a region containing PxY repeats in Alix/AIP1, which is required for the subcellular punctate distribution of the amino-terminal truncation form of Alix/ AIP1. J Biochem. 2004; 135:117-28.

31. Siegel RL, Miller KD, Jemal A. Cancer Statistics, 2017. CA Cancer J Clin. 2017; 67:7-30.

32. Siegel RL, Miller KD, Jemal A. Cancer statistics, 2018. CA Cancer J Clin. 2018; 68:7-30.

33. Su D, Xu H, Feng J, Gao Y, Gu L, Ying L, Katsaros D, Yu H, Xu S, Qi M. PDCD6 is an independent predictor of progression free survival in epithelial ovarian cancer. J Transl Med. 2012; 10: 31.

34. Suzuki H, Kawasaki M, Inuzuka T, Okumura M, Kakiuchi T, Shibata H, Wakatsuki S, Maki M. Structural basis for $\mathrm{Ca} 2+$-dependent formation of ALG-2/Alix peptide complex: $\mathrm{Ca} 2+/ \mathrm{EF} 3-$ driven arginine switch mechanism. Structure. 2008; 16:1562-73.

35. Vito P, Lacana E, D'Adamio L. Interfering with apoptosis: $\mathrm{Ca}(2+)$-binding protein ALG-2 and Alzheimer's disease gene ALG-3. Science. 1996; 271:521-5.

36. Vito P, Pellegrini L, Guiet C, D'Adamio L. Cloning of AIP1, a novel protein that associates with the apoptosis-linked gene ALG-2 in a Ca2+-dependent reaction. J Biol Chem. 1999; 274:1533-40.

37. Wang X, Zuo D, Yuan Y, Yang X, Hong Z, Zhang R. MicroRNA-183 promotes cell proliferation via regulating programmed cell death 6 in pediatric acute myeloid leukemia. J Cancer Res Clin Oncol. 2017; 143:169-80.

38. Yamada Y, Arao T, Gotoda T, Taniguchi H, Oda I, Shirao K, Shimada Y, Hamaguchi T, Kato K, Hamano T, Koizumi F, Tamura T, Saito D, et al. Identification of prognostic biomarkers in gastric cancer using endoscopic biopsy samples. Cancer Sci. 2008; 99:2193-9.

39. Yamasaki A, Tani K, Yamamoto A, Kitamura N, Komada M. The Ca2+-binding protein ALG-2 is recruited to endoplasmic reticulum exit sites by Sec31A and stabilizes the localization of Sec31A. Mol Biol Cell. 2006; 17:4876-87.

40. Yoon JH, Choi YJ, Kim SG, Nam SW, Lee JY, Park WS. Programmed cell death 6 (PDCD6) as a prognostic marker for gastric cancers. Tumour Biol. 2012; 33:485-94.

41. Yuan L, Li S, Zhou Q, Wang D, Zou D, Shu J, Huang Y. MiR-124 inhibits invasion and induces apoptosis of ovarian cancer cells by targeting programmed cell death 6 . Oncol Lett. 2017; 14:7311-7.

42. Yuan M, Song Y, You D, Li Q, Zhang Y, Zhou B, Zhang L, Xi M. Association between single nucleotide polymorphisms in the programmed cell death 6 gene and the risk of endometrial cancer in Chinese Han women. Int $\mathrm{J}$ Clin Exp Pathol. 2017; 10:11169-78.

43. Zhang L, Chen X, Liu B, Han J. MicroRNA-124-3p directly targets PDCD6 to inhibit metastasis in breast cancer. Oncol Lett. 2018; 15:984-90.

44. Zhou B, Bai P, Xue H, Zhang Z, Shi S, Zhang K, Wang Y, Wang K, Quan Y, Song Y, Zhang L. Single nucleotide polymorphisms in PDCD6 gene are associated with the development of cervical squamous cell carcinoma. Fam Cancer. 2015; 14:1-8.

45. Zhou B, Zhang P, Tang T, Zhang K, Wang Y, Song Y, Liao $\mathrm{H}$, Zhang L. Prognostic value of PDCD6 polymorphisms and the susceptibility to bladder cancer. Tumour Biol. 2014; 35:7547-54. 